\section{Cervical grasping and stabilising forceps}

I was very interested to read Speedie et al.'s report ${ }^{1}$ on their carefully conducted randomised trial of two stabilising forceps for the insertion of intrauterine contraception (IUC). Their finding that there is no significant difference in the pain experienced on application of single-toothed volsellum forceps and Littlewood forceps in the specific group of women selected, those with at least one vaginal delivery, is interesting, and was certainly worth establishing objectively. However, I was disappointed that the instrument selected by them as the comparator for the obviously 'traumatic' single-toothed volsellum was the Littlewood forceps rather than a commonly-used alternative, the Judd-Allis forceps.

The Judd-Allis forceps (Figure 1A) is a lengthened form of the Allis forceps that is commonly used as a tissue grasping forceps in all fields of surgery. Its advantage over both the single-toothed volsellum and the Littlewood forceps is that the narrow diameter and length of its shanks create a 'springiness' that permits its gentle application to tissues. Although there is some difference in the pattern of the tips between manufacturers, in general the tips are wider than those of Littlewood forceps, with a greater number of finer teeth (3-5 teeth, rather than just 2), giving a wider application area and lesser depth of epithelial penetration, and therefore a better spread of applied force on the cervical epithelium (Figure 1B). It has its wider tip and fine teeth in common with the Teale tenaculum that is popular in the USA and that was used as the atraumatic forceps in Doty and MacIsaac's ${ }^{2}$ earlier randomised trial to which the authors referred. A further benefit is that because of the small transverse measurement of its jaw, both when open and when closed, the Judd-Allis forceps occupies less space within the upper vagina than either a single-toothed volsellum or Littlewood forceps, allowing easier access to the cervical os.

I cannot, of course, quote a randomised trial of the use of this instrument, but my very strong opinion (RCOG Evidence Level 4), ${ }^{3}$ based on 40 years' experience as a gynaecologist with a special interest in contraception, is that the Judd-Allis forceps is easily the most appropriate instrument for grasping and manipulating the cervix in the conscious patient. Over the years I have used it extensively for IUC insertion, Pipelle ${ }^{\circledR}$ endometrial aspiration and for steadying the cervix for stromal and paracervical local anaesthetic injection for colposcopic procedures. The forceps is applied to the anterior cervical lip transversely, to grasp only the cervical skin and not the stroma. It is closed slowly, to just two clicks of its ratchet. The patient is told that she may "feel a pinch" - and that is just what she feels, if she feels anything at all. For patients who are very anxious (perhaps because of previous adverse experiences), injection of just $0.1 \mathrm{ml}$ of local anaesthetic into the epithelium is sufficient to prevent all pain of the forceps application.

I agree with colleagues who are "experts in the field", ${ }^{4}$ as quoted in Speedie et al.'s introduction, that the forceps used to grasp the cervix for IUC insertion should ideally be atraumatic. In that regard, I would submit that the Judd-Allis forceps is significantly less traumatic than the Littlewood forceps. In my opinion it would be doing women a disservice if Littlewood forceps were now to be favoured over Judd-Allis forceps simply because they were the forceps that happened to have been chosen for this randomised trial.

\section{David H Horwell, FRCOG, Hon FFSRH}

Consultant Gynaecologist, Harpenden, UK; dhhjournal@mail.com

Advisory Editor, Journal of Family Planning and Reproductive Health Care

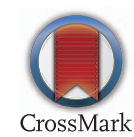

Published Online First 29 November 2016

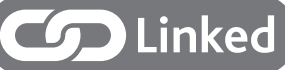

http://dx.doi.org/10.1136/ffprhc-2016-101446

- http://dx.doi.org/10.1136/jpprhc-2016-101683

J Fam Plann Reprod Health Care 2017;43:77. doi:10.1136/jprhc-2016-101656

\section{REFERENCES}

1 Speedie JMM, Mansour D, Landy R, et al. A randomised trial comparing pain and ease of use of two different stabilising forceps for insertion of intrauterine contraception.

J Fam Plann Reprod Health Care 2016;42: 241-246.

2 Doty N, MacIsaac L. Effect of an atraumatic vulsellum versus a single-tooth tenaculum on pain perception during intrauterine device insertion: a randomized controlled trial. Contraception 2015;92:567-571.

3 Royal College of Obstetricians and Gynaecologists (RCOG). Development of RCOG green-top guidelines: producing a clinical practice guideline. November 2006. https://www.rcog.org.uk/globalassets/ documents/guidelines/clinical-governanceadvice/clinical-governance-advice-1c.pdf [accessed 18 October 2016].

4 Guillebaud J, MacGregor A. Contraception: Your Questions Answered (6th edn). Oxford, UK: Churchill Livingstone, 2013.

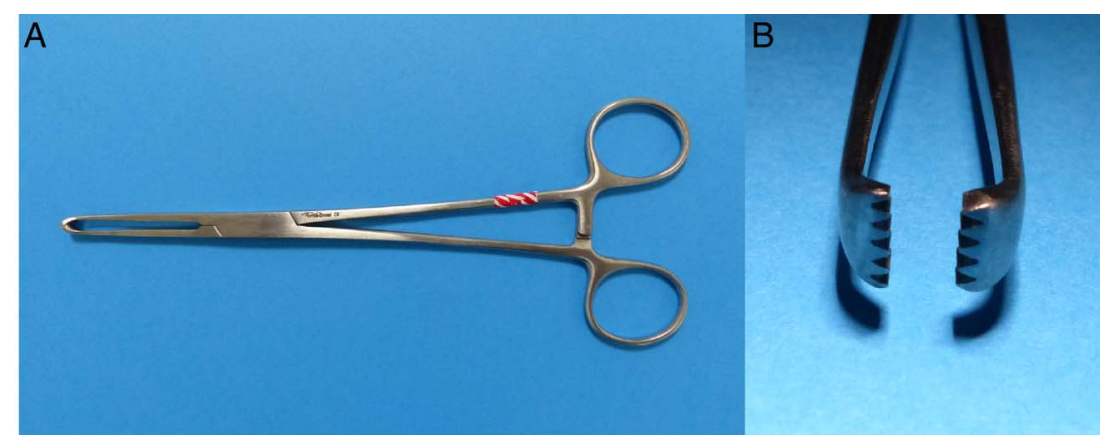

Figure 1 (A) Judd-Allis forceps. (B) View of tip of Judd-Allis forceps. 